\section{COVID-19 and diabetes mellitus patients}

\author{
Pooyan Afzali Harsini', Ali Khani Jeihooni2*, Gholamreza Imani ${ }^{3}$, Saeed \\ Hamzehie $^{4}$, Hadis Safaei Moghadam ${ }^{5}$, Fatemeh Alimohammadi Rozveh ${ }^{5}$ \\ and Sahar Alizadegan ${ }^{5}$ \\ 'Department of Public Health, School of Health, Kermanshah University of Medical Sciences, \\ Kermanshah, Iran \\ ${ }^{2}$ Nutrition Research Center, Department of Public Health, School of Health, Shiraz University of Medical \\ Sciences, Shiraz, Iran \\ ${ }^{3} \mathrm{MD}$, Department of Medicine, School of Medicine, Kermanshah University of Medical Sciences, \\ Kermanshah, Iran \\ ${ }^{4} \mathrm{MD}$, Internal Medicine Specialist, Department of Medicine, School of Medicine, Kermanshah University \\ of Medical Sciences, Kermanshah, Iran \\ ${ }^{5}$ Student Research Committee, Lorestan University of Medical Sciences, Khorramabad, Iran
}

Received: 19 December, 2021

Accepted: 21 January, 2022

Published: 22 January, 2022

*Corresponding author: Dr. Ali Khani Jeihooni, Nutrition Research Center, Department of Public Health, School of Health, Shiraz University of Medical Sciences, Shiraz, Iran E-mail: Khani_1512@yahoo.com ORCID: https://orcid.org/0000-0003-1689-6895 Copyright License: (c) 2022 Harsini PA, et al. This is an open-access article distributed under the terms of the Creative Commons Attribution License, which permits unrestricted use, distribution, and reproduction in any medium, provided the original author and source are credited.

https://www.peertechzpublications.com

\section{Check for updates}

\section{Introduction}

Coronavirus (COVID-19) is an encapsulated virus with a self-positive-sense RNA genome that is proven to cause respiratory disease in humans. Coronaviruses (COVID-19) are a type of virus that infects the respiratory tract [1]. In most immunocompetent individuals, infection with human COVID-19 results in a moderate upper respiratory infection in the majority of cases. The outbreaks of the Severe Acute Respiratory Syndrome (SARS) in Guangdong province, China, in 2003 and the Middle East Respiratory Syndrome (MERS) in Middle Eastern countries a decade later were caused by two highly virulent COVID-19. SARS-CoV and MERS-CoV were discovered to be the causative agents of SARS and MERS, respectively [2]. In December of this year, a novel coronavirus, SARS-CoV-2, was discovered as the pathogen responsible for coronavirus disease (COVID-19) in Wuhan, China, according to the Chinese government Park SY, et al. [3] It mostly affects the respiratory tract, as well as the severity of the illness, which can range from undiagnosed or moderate or severe disease in some patients. Even though the current case mortality rate for COVID-19 is estimated to be less than 5 percent, up to 1518 majority of patients may have become severely or severely unwell, with some requiring Intensive Care Unit (ICU) treatment and mechanical breathing [4]. Currently, 266,163,340 cases discovered, and 5,271,960 cases have died worldwide [5]. The likelihood of acute infection and consequent mortality in people with comorbidities rises with age. Increased acute illness, respiratory failure, and increased mortality are all related to Diabetes Mellitus (DM) as unique comorbidity, according to the majority of the existing research [6]. A study from China by Alhazzani W, et al. found that 173 of 1099 confirmed COVID-19 patients had acute disease; patients with severe disease had a greater frequency of DM (16.2\%) than those who had the acute disease (5.7\%) [6]. Additionally, the biggest series of COVID-19 cases reported by the Chinese Center for Disease Control and Prevention, which included 72,314 cases, diabetic patients had a greater fatality rate than those without diabetes (7.3\% in DM compared to $2.3 \%$ overall) [7]. Another study by Iacobellis G, et al. showed that $51 \%$ of COVID-19 patients have been diagnosed with hyperglycemia [8]. Diabetes prevalence has been shown to range between $5 \%$ and $20 \%$ in COVID-19 patients in the Bornstein SR, et al. study. Diabetes is also connected with an increased risk of severe to life-threatening disease in $14-32 \%$ of COVID-19 patients [9].

\section{Relating between age and DM in COVID-19 patients}

While it is reasonable to expect that patients with DM are older than those without DM, and growing age has repeatedly been associated with increased mortality in COVID-19, the majority of the aforementioned studies did not control for age. Nonetheless, diabetes has consistently been linked to a poor outcome in various viral illnesses, most notably seasonal influenza, pandemic influenza A H1N1 (2009), Severe Acute Respiratory Syndrome (SARS), and Middle East Respiratory 
Syndrome (MERS) [10,11]. As a study has done in Mexico, the probability of death from DM reduced with age in adult patients infected with COVID-19 in Mexico. There has been no correlation between diabetes and mortality in inpatients aged 80 years or older. These results should be replicated in more populations [12]. In another study have done in us, $26.8 \%$ aged 65 years and older, a group at higher risk of mortality from COVID-19 had DM. McMichael TM, et al. [13] Between January 1, 2020, and December 1, 2021, approximately 206,038 of the 779,402 deaths caused by COVID-19 in the United States were among people aged 85 years and older. This statistic depicts the number of deaths caused by coronavirus disease 2019 (COVID-19) in the United States from January 2020 to December 2021, by age group. Elflein J [14]. Also indicated, age was identified as a predictive factor for intubation [15]. However in another study done by Coronado seems On day 7, there was no evidence that age was a significant predictor for orotracheal intubation and/or death [16]. A study is done in Iran showed that Patients with COVID-19 who were older than 60 years and younger than 20 years had 3.4 and $1.9 \%$ greater odds of death, respectively, as compared to patients in the 20-to-40-year age range, indicating a higher risk of mortality in elderly and younger patients with diabetes, according to the study. Male diabetic patients had a death rate that was 34 percent higher than female diabetic patients [17].

\section{Is diabetes mellitus related to COVID-19-related mor- tality and severity?}

As a meta-analysis study was done, diabetes showed a substantially linked with acute COVID-19 as well as COVID-19 death. In the first place, because diabetes can cause severe COVID-19 in diabetics, prevention is essential. In order to avoid contracting a coronavirus infection, diabetic individuals should be advised by their doctors to practice social seclusion and good hand cleanliness.

Second, diabetic individuals should be tested for COVID-19 more frequently in out-patient clinics, and the threshold for testing should be lowered.

Any COVID-19 patient who also has diabetes should be considered potentially dangerous, even if he or she has only mild or no symptoms at the time of admission. These individuals will necessitate more frequent monitoring and a lower threshold for hospitalization and ICU admission. [18]. Another study showed that age seemed to be a risk factor for death and orotracheal intubation in both the total cohort and diabetic patients in univariate and multivariate analyses. These findings corroborate earlier research. Older age has also been linked to a higher prevalence of various comorbidities [19]. Another important point is those diabetic patients were shown to be more likely than non-diabetic patients to have more comorbidities and worse clinical conditions. Their need for intubation and fatality rates were found to be connected not just with cardiovascular and renal comorbidities, but also with smoking/past smoking and neurologic disorders, among other factors. Interestingly, in univariate analysis, the presence of Chronic Kidney Disease (CKD) and the necessity for Prisma were both found to be risk factors for death and intubation outcomes in diabetic individuals. Furthermore, in multivariate analysis, Chronic Kidney Disease (CKD) is found to be an independent risk factor for intubation [20]. The particular underlying processes that contribute to the increased mortality rate seen in participants who were infected with DM-SARS-CoV2 are still unknown. Several aspects connected to diabetes have been taken into consideration. Persons suffering from diabetes have pulmonary dysfunction due to decreased lung volume and lower pulmonary diffusing capacity. They also have difficulty controlling their breathing and have low bronchomotor tone and noradrenergic innervation [21]. Another factor is associated is D-dimer which according to the findings, a decreased lymphocyte and platelet count, as well as elevated D-dimer levels, were the most accurate predictors of an overall higher mortality. The $\mathrm{D}$-dimer test is the most accurate predictor of overall mortality among the latter components. Emerging evidence suggests that, in addition to Deep Venous Thrombosis (DVT), elevated D-dimer levels in COVID-19 patients may be the expression of capillary microthrombi, which are caused by pulmonary capillary endothelial injury, and that this may contribute to the increased risk of death in these patients [22]

\section{Symptoms in diabetic COVID-19 patients}

A systematic review and meta-analysis of clinical symptoms associated with COVID19 revealed that fever, cough, and dyspnea were the most frequent symptoms [23]. Among this study, it appears that dyspnea symptoms are more common in diabetes in-patients (45.6 percent versus 58.25 percent), however, this difference is not statistically significant. Because it is placed within a 95 percent confidence interval of the prevalence of meta-analysis, it is considered reliable. Other symptoms, on the other hand, are less severe than in recent trials (fever: 24.6 percent vs $88.7 \%$, cough: 44.58 percent vs 57.6 percent). According to the findings of this study, only fever is considerably lower in diabetes patients when compared to the results of the meta-analysis, which may be due to an immunological response. Rezaei N, et al. [17] COVID-19 patients typically show symptoms 5-6 days after infection. SARSCoV-2, like SARS-CoV and MERS-CoV, causes mild symptoms for 2 weeks but can progress to serious infection, along with a systemic inflammatory response syndrome, acute respiratory distress syndrome, multi-organ involvement, and shock [7].

\section{New finding}

- Diabetes appears to be on the rise among SARS-CoV-2 patients.

- In the initial viral attachment step, vulnerability to SARS appears to be predominantly determined by the spike's affinity to bind host ACE2 receptors (ACE2r) in target tissues.

- Diabetic patients are commonly affected by low-grade chronic inflammation, which can result in excessive cytokine storms, a bad outcome from COVID-19, and an increased risk of death.

- The SARS-CoV-2 internalization receptor, ACE2r, works with the host's TMPRSS2 membrane protease to prime the virus's spike S protein for cell entrance. 
- Diabetics must adhere to a strict dietary regimen.

- According to the American Diabetes Association, exercise should be continued at home as well as at the gym.

- Sporting activity helps to improve glucose levels management in type 2 diabetes by increasing muscle glucose uptake fivefold through insulin-independent pathways. It also significantly reduces cardiovascular risk factors and helps with weight loss. Adults with type 2 diabetes should preferably engage in both aerobic and resistance exercise training in order to get the best possible glycemic and health outcomes.

\section{Conclusion}

In this study, we studied several research works worldwide and found important facts about COVID-19 and diabetic patients. COVID-19 is a continuing epidemic, with new information on the disease emerging regularly. Diabetes is an important comorbid condition for COVID-19, and diabetic patients must take the required precautions to avoid infection. Diabetes and COVID-19 are both medical disorders that affect people all over the world. Diabetes individuals are more vulnerable to the severity of COVID-19 than the general population.

Diabetes is related to a two-fold increased risk of mortality and a two-fold increased risk of COVID-19 severity in patients with COVID-19. Our advice is broken into two parts:

\section{Prevention}

Create home learning and remote-control systems.

Gliptin medicines should be used in moderation.

Blood glucose levels must be monitored and attempted to be controlled.

Limit the use of ACEI medication classes.

To reduce infection, avoid needless hospitalizations.

Improve your nutrition and eat a healthy diet.

\section{Following an infection}

keep an eye on the symptoms.

Every 8 hours, the blood glucose level is monitored.

ARDS surveillance

Reduced occurrences of harmful drug reactions

Nutritional considerations

Long-term monitoring of COVID-19 side effects.

\section{References}

1. Sheahan TP, Sims AC, Leist SR, Schäfer A, Won J, et al. (2020) Comparative therapeutic efficacy of remdesivir and combination lopinavir, ritonavir, and interferon beta against MERS-CoV. Nature Communications 11: 1-14. Link: https://go.nature.com/3IFuWzx
2. Zhong N, Zheng B, Li Y, Poon L, Xie Z, et al. (2003) Epidemiology and cause of severe acute respiratory syndrome (SARS) in Guangdong, People's Republic of China. Lancet 362: 1353-1358. Link: https://bit.ly/3IpXSva

3. Park SY, Kim JH, Kim HJ, Seo B, Kwon OY, et al. (2018) High prevalence of asthma in elderly women: findings from a Korean national health database and adult asthma cohort. Allergy, Asthma Immunol Res 10: 387-396. Link: https://bit.ly/3FNCYo1

4. Sun P, Qie S, Liu Z, Ren J, Li K, et al. (2020) Clinical characteristics of hospitalized patients with SARS-CoV-2 infection: a single arm meta-analysis. J Med Virol 92: 612-617. Link: https://bit.ly/3KvWclx

5. Coronavirus Cases Link: https://bit.ly/3Kp8GLT

6. Alhazzani W, Møller M, Arabi Y, Loeb M, Gong M, et al. (2020) Surviving Sepsis Campaign: guidelines on the management of critically ill adults with Coronavirus Disease 2019 (COVID-19). Intensive Care Medicine 46: 854-887. Link: https://bit.ly/3fHuYuf

7. Wu Z, McGoogan JM (2020) Characteristics of and important lessons from the coronavirus disease 2019 (COVID-19) outbreak in China: summary of a report of 72314 cases from the Chinese Center for Disease Control and Prevention. JAMA 323: 1239-1242. Link: https://bit.ly/3FPvssO

8. Lacobellis G, Penaherrera CA, Bermudez LE, Mizrachi EB (2020) Admission hyperglycemia and radiological findings of SARS-CoV2 in patients with and without diabetes. Diabetes Res Clin Pract 164: 108185. Link: https://bit.ly/3AhGupA

9. Bornstein SR, Rubino F, Khunti K, Mingrone G, Hopkins D, et al. (2020) Practical recommendations for the management of diabetes in patients with COVID-19. Lancet Diabetes Endocrinol 8: 546-550. Link: https://bit.ly/3g0Fwot

10. Song Z, Xu Y, Bao L, Zhang L, Yu P, et al. (2019) From SARS to MERS, thrusting coronaviruses into the spotlight. Viruses 11: 59. Link: https://bit.ly/3AhVmEe

11. Yang J, Feng Y, Yuan M, Yuan S, Fu H, et al. (2006) Plasma glucose levels and diabetes are independent predictors for mortality and morbidity in patients with SARS. Diabet Med 23: 623-628. Link: https://bit.ly/3nKyhVO

12. Woolcott OO, Castilla-Bancayán JP (2021) The effect of age on the association between diabetes and mortality in adult patients with COVID-19 in Mexico. Scientific Reports 11: 8386. Link: https://go.nature.com/3fMbSD0

13. McMichael TM, Clark S, Pogosjans S, Kay M, Lewis J, et al. (2020) COVID-19 in a long-term care facility-King County, Washington, February 27-March 9 2020. MMWR Morb Mortal Wkly Rep 69: 339-342. Link: https://bit.ly/3FOByJG

14. Elflein J (2021) COVID-19 deaths reported in the U.S. as of December 1, 2021, by age. Link: https://bit.ly/35aEMLb

15. De Vita N, Scotti L, Cammarota G, Racca F, Pissaia C, et al. (2021) Predictors of intubation in COVID-19 patients treated with out-of-ICU continuous positive airway pressure. Pulmonology. Link: https://bit.ly/3rB1|Ai

16. Cariou B, Hadjadj S, Wargny M, Pichelin M, Al-Salameh A, et al. (2020) Phenotypic characteristics and prognosis of inpatients with COVID-19 and diabetes: the CORONADO study. Diabetologia 63: 1500-1515. Link: https://bit.ly/3HOVnyQ

17. Rezaei N, Montazeri F, Malekpour MR, Ghanbari A, Azadnajafabad S, et al. (2021) COVID-19 in patients with diabetes: factors associated with worse outcomes. J Diabetes Metab Disord 20: 1-10. Link: https://bit.ly/33DzqHR

18. Kumar A, Arora A, Sharma P, Anikhindi SA, Bansal N, et al. (2020) Is diabetes mellitus associated with mortality and severity of COVID-19? A meta-analysis. Diabetes Metab Syndr 14: 535-545. Link: https://bit.ly/3FP9qX9

19. Ho FK, Petermann-Rocha F, Gray SR, Jani BD, Katikireddi SV, et al. (2020) Is older age associated with COVID-19 mortality in the absence of other risk factors? General population cohort study of 470,034 participants. PLoS One 15: e0241824. Link: https://bit.ly/3tNw7Zk

Citation: Harsini PA, Jeihooni AK, Imani G, Hamzehie S, Moghadam HS, et al. (2022) COVID-19 and diabetes mellitus patients. Glob J Obes Diabetes Metab Syndr 9(1): 007-010. DOI: https://dx.doi.org/10.17352/2455-8583.000055 
20. Tamura RE, Said SM, de Freitas LM, Rubio IGS (2021) Outcome and death risk of diabetes patients with Covid-19 receiving pre-hospital and in-hospital metformin therapies. Diabetol Metab Syndr 13: 76. Link: https://bit.ly/3fMbAfo

21. Corona G, Pizzocaro A, Vena W, Rastrelli G, Semeraro F, et al. (2021) Diabetes is most important cause for mortality in COVID-19 hospitalized patients: Systematic review and meta-analysis. Rev Endocr Metab Disord 22: 275-296. Link: https://bit.ly/3FN066a
22. Poissy J, Goutay J, Caplan M, Parmentier E, Duburcq T, et al. (2020) Pulmonary embolism in patients with COVID-19: awareness of an increased prevalence. Circulation 142: 184-186. Link: https://bit.ly/3fKlqhY

23. Rodriguez-Morales AJ, Cardona-Ospina JA, Gutiérrez-Ocampo E, VillamizarPeña R, Holguin-Rivera Y, et al. (2020) Clinical, laboratory and imaging features of COVID-19: A systematic review and meta-analysis. Travel Med Infect Dis 34: 101623. Link: https://bit.ly/3GNE1W 